\title{
Gas exchange response to a PAF receptor antagonist, SR 27417A, in acute asthma: A pilot study
}

\author{
F.P. Gómez*, R.M. Marrades*, R. Iglesia*, J. Roca*, J.A. Barberà*, \\ K.F. Chung**, R.M. Rodriguez-Roisin*
}

Gas exchange response to a PAF receptor antagonist, SR 27417A, in acute asthma: A pilot study. F.P Gómez, R.M. Marrades, R. Iglesia, J. Roca, J.A. Barberà, K.F. Chung, R. Rodriguez-Roisin. (C) ERS Journals Ltd 1999.

ABSTRACT: The pathogenic role of platelet-activating factor (PAF) in asthma has been questioned due to the limited or negative efficacy of PAF antagonists; however, in acute asthma (AA), where the endogenous release of PAF may be enhanced, the effects of PAF antagonist receptors have not been investigated. It was postulated that inhaled PAF provokes gas exchange defects in mild asthma likely to be related to airway vascular leakage.

The response to a potent, selective PAF receptor antagonist, SR 27471A, on pulmonary gas exchange was studied, more specifically ventilation-perfusion $\left(V_{\mathrm{A}^{\prime}} / Q^{\prime}\right)$ distributions, in patients with $\mathrm{AA}$ within $48 \mathrm{~h}$ of hospitalization. A randomized, double-blind, placebo-controlled, parallel group $(n=6$, each) design was used. After baseline measurements, either placebo or SR $27417 \mathrm{~A}(20 \mathrm{mg}$, orally) was administered and measurements were repeated $3 \mathrm{~h}$ later. Conventional anti-asthma medication was not interrupted.

Despite a near-complete inhibition of the in vitro, platelet aggregation tests by 40 nM PAF (mean \pm SEM from $72 \pm 9$ to $6 \pm 2 \%$ ) and $80 \mathrm{nM}$ PAF (from $81 \pm 7$ to $6 \pm 3 \%$ both p $<0.01$ ) by SR $27471 \mathrm{~A}$ indicating a good bioactivity of the compound, no significant changes in baseline forced expiratory volume in one second, $(40 \pm 6 \%)$, respiratory system resistance $\left(6.2 \pm 0.7 \mathrm{cmH}_{2} \mathrm{O} \cdot \mathrm{L}^{-1} \cdot \mathrm{s}\right)$, alveolar-arterial pressure difference for oxygen $(5.2 \pm 0.4 \mathrm{kPa})$, arterial oxygen tension $(9.0 \pm 0.5 \mathrm{kPa})$ or $V_{\mathrm{A}^{\prime}} / Q^{\prime}$ distributions, as expressed by the dispersion of pulmonary blood flow $(\operatorname{LogsD} Q, 1.07 \pm 0.09$; normal values $<0.60$ ), were observed.

It is concluded that SR 27417A has limited value when added to the conventional treatment of acute asthma. These findings minimize the potential pathogenic role of endogenous platelet-activating factor as a relevant mediator of airway inflammation during acute asthma.

Eur Respir J 1999; 14: 622-626.
*Servei de Pneumologia i Al.lèrgia Respiratòria, Dept de Medicina, Institut d'Investigacions Biomédiques August Pi i Sunyer (IDIBAPS), Hospital Clinic, Universitat de Barcelona, Barcelona, Spain. **National Heart and Lung Institute, Imperial College School of Medicine, London, UK.

Correspondence: R. Rodriguez-Roisin Servei de Pneumologia i Al.lèrgia Respiratòria Hospital Clinic Villarroel 170. 08036 Barcelona Spain. Fax: 34932275404

Keywords: Acute asthma therapy mediators of inflammation

platelet-activating factor antagonists status asthmaticus

ventilation-perfusion inequality

Received: December 291998

Accepted after revision May 61999

Supported by Grant 9710143 from the Fondo de Investigación Sanitaria (FIS) and the Comissionat per a Universitats $\mathrm{i}$ Recerca de la Generalitat de Catalunya (1997 SGR 0086) and a grant in aid from Sanofi. Winthrop. F.P. Gómez, was supported by a Predoctoral Research Fellowship from the European Respiratory Society (ERS) (1996)
In order to determine the pathogenic role of any putative inflammatory mediator in asthma, Koch's related postulates have been applied [1]. Platelet-activating factor (PAF), a potent mediator invoked in the pathogenesis of asthma, fulfils many of these criteria. Inflammatory cells involved in asthma including both neutrophils and eosinophils can synthesize PAF [2] and PAF has been retrieved from bronchoalveolar lavage fluid of patients with bronchial asthma [3]. Moreover, inhaled PAF evokes some of the clinical hallmarks of natural, spontaneously occurring asthma, such as bronchoconstriction [4], bronchial hyperresponsiveness [5], and gas exchange abnormalities [4, 6]. Despite several studies having shown that some of the PAF-induced effects can be reversed by PAF antagonists $[7,8]$, the role of PAF in the pathogenesis of asthma has been questioned due to the limited and/or negative efficacy shown in randomized controlled trials in patients with mild to moderate asthma $[9,10]$.
Recently, the pathogenic role of PAF in asthma has been revisited because of newer aspects on PAF-induced proinflammatory characteristics [11] and genetic evidence showing that the deficiency of PAF acetylhydrolase, which catalyses the degradation of PAF, is related to asthma severity in children [12]. So far, the effects of PAF antagonists in acute asthma (AA) have not been investigated; however, this clinical category of severe asthma may well represent the most appropriate setting to test the efficacy of anti-PAF compounds since the endogenous release of PAF together with other mediators may be orchestrated more prominently under more critical, dismal clinical conditions. The present study was undertaken to assess the effect of a new, potent, selective PAF receptor antagonist, SR 27471A, on airflow rates, respiratory system resistance (Rrs) and gas exchange abnormalities, in patients with AA, the primary end-point outcome being arterial blood gases and their major intrapulmonary 
determinant, ventilation-perfusion $\left(V \mathrm{~A}^{\prime} / Q^{\prime}\right)$ imbalance. It has recently been shown that, in a laboratory-induced model of PAF challenge in patients with mild asthma, this compound fully antagonized all PAF-induced systemic, cellular and lung function abnormalities [13].

\section{Methods}

\section{Study population}

Twelve nonsmoking patients, six in the placebo group (five females, one male) (mean \pm SEM age $29 \pm 5$ yrs) and six in the SR 27417A group (four females, two males) (age $35 \pm 4$ yrs), who needed hospitalization for an acute exacerbation of asthma were recruited for the study, which was approved by the Ethics Research Committee of the Hospital Clinic. Both treatment and decision concerning hospitalization, defined as a stay in hospital for $>24 \mathrm{~h}$, were carried out by attending physicians not involved in the research team and following standard clinical (persistence of dyspnoea, wheezing and/or accessory muscle use) and functional (peak expiratory flow rate (PEF) $<60 \%$ of predicted [14]) $\left(120 \pm 15 \mathrm{~L} \cdot \mathrm{min}^{-1} ; 24 \pm 3 \%\right.$ pred $)$ criteria, with or without the presence of respiratory failure arterial oxygen tension $\left(\mathrm{Pa}_{\mathrm{a}} \mathrm{O}_{2}\right)<8 \mathrm{kPa}$ while breathing room air) [15]. All subjects gave informed written consent after the purpose, risks and potential benefits of the study were explained to them. Patients were included in the study within $48 \mathrm{~h}$ after admission (mean $26.3 \pm 2.8 \mathrm{~h}$; median $25 \mathrm{~h}$, range 9-40 h, according to the following criteria: $<50$-yrs-old; lack of respiratory infection, as assessed by the absence of fever, purulent mucous secretions, and/or chest radiography infiltrates; persistence of asthma symptoms and severe airflow limitation in spite of an energetic standard therapy including nebulized salbutamol, $5.0 \mathrm{mg}$ every $6 \mathrm{~h}$, intravenous methylprednisolone $60 \mathrm{mg}$ every $6 \mathrm{~h}$, and continuous high-flow oxygen therapy, if needed; and absence of any systemic or cardiopulmonary disease other than asthma. All of the patients recovered completely from the acute episode and were discharged from hospital without complications (mean duration of stay, $5.7 \pm 1.5$ days)

\section{Measurements}

Blood samples were collected anaerobically through a catheter inserted into the radial artery. $\mathrm{Pa}, \mathrm{O}_{2}$, arterial carbon dioxide tension $\left(\mathrm{Pa}_{\mathrm{a}} \mathrm{CO}_{2}\right)$ and $\mathrm{pH}$ were analysed in duplicate using standard electrodes (Model 865; CIBA-Corning), Medfield, MA, USA). Haemoglobin concentration was measured by a Co-oximeter (Model 865; CIBA-Corning. Oxygen uptake $\left(V^{\prime} \mathrm{O}_{2}\right)$ and $\mathrm{CO}_{2}$ production $\left(V^{\prime} \mathrm{CO}_{2}\right)$ were calculated from mixed expired $\mathrm{O}_{2}$ and $\mathrm{CO}_{2}$ (CPX System; Medical Graphics, St Paul, MN, USA). Minute ventilation $\left(V^{\prime} \mathrm{E}\right)$ and respiratory rate (RR) were measured using a calibrated Wright spirometer (Respirometer MK8; BOCMedical, Essex, UK). The alveolar-arterial pressure difference for oxygen $\left(P \mathrm{~A}-\mathrm{a}, \mathrm{O}_{2}\right)$ was calculated according to the standard alveolar gas equation using the measured respiratory exchange ratio $(\mathrm{R})$.

The multiple inert gas elimination technique (MIGET) was used to estimate the distributions of ventilationperfusion $\left(V \mathrm{~A}^{\prime} / Q^{\prime}\right)$ ratios without sampling mixed venous inert gases in the customary manner, a modality that has shown similar accuracy [16]. With this approach, cardiac output $\left(Q^{\prime}\right)$ needs to be directly measured by dye dilution technique (DC-410; Waters Instruments Inc, Rochester, MN, USA) using a $5.0-\mathrm{mg}$ bolus of indocyanine green injected through a catheter placed percutaneously in an arm vein, while mixed venous inert gas concentrations are computed from mass balance equations [16]. The duplicate samples of each set of measurements were treated separately, the final data resulting in the average of variables determined from both $V \mathrm{~A}^{\prime} / Q^{\prime}$ distributions at each time point.

Total white cell counts in arterial blood were measured with a Technicon H. $1^{\mathrm{TM}}$ System (Technicon; Tarytown, New York, NY, USA), while platelet aggregation tests were obtained with a Hitachi Aggrecorder (Hitachi/Aggrecorder PA3210; Hitachi, Kyoto, Japan), as previously reported in detail [13].

Total resistance of the respiratory system ( $R r s)$ was measured by the forced oscillation technique and its analysis restricted to $8 \mathrm{~Hz}$, as reported elsewhere [4, 6, 13]. A three-lead electrocardiogram, heart rate (HR) and systemic pressure (Ps) and arterial oxygen saturation through a pulseoximeter (HP M1166A; Hewlett-Packard, Boblingen, Germany) were continuously recorded throughout the whole study (HP 7830A Monitor and HP 7754B Recorder; Hewlett-Packard, Waltham, MA, USA). Maintenance of steady-state conditions was demonstrated by stability $( \pm 5 \%)$ of both ventilatory and haemodynamic variables, by the close agreement between duplicate measurements of mixed expired and arterial $\mathrm{O}_{2}$ and $\mathrm{CO}_{2}$, and by the good adjustment of the inert gas measurements (mean residual sum of squares (RSS) were $\leq 7.0$ in all instances) (mean 2.0 0.3 ; range, 0.7-7.0). Last in sequence, forced spirometric measurements were made using a pneumotachograph spirometer (Model Datospir 92; Sibel, Barcelona, Spain).

\section{Study design}

A randomized, double-blind, placebo-controlled, twogroup design was used. All measurements were made in the semirecumbent position breathing room air, after ensuring adequate steady-state conditions (see above). Standard asthma medication was not interrupted during the study. Two hours after the last dose of nebulized salbutamol and systemic glucocorticosteroids (at 08:00-10:00 $\mathrm{h}$ ), baseline measurements were taken. Immediately thereafter, placebo/SR 27417A (20 mg) was administered orally and all measurements were repeated $3 \mathrm{~h}$ later. A final set of all but $V \mathrm{~A}^{\prime} / Q^{\prime}$ distributions and platelet aggregation measurements, was carried out $3 \mathrm{~h}$ later, that is $6 \mathrm{~h}$ after placebo/SR 27417A intake and $2 \mathrm{~h}$ after a second dose (5.0 $\mathrm{mg}$ ) of nebulized salbutamol and systemic glucocorticosteroids. This time point was added to assess whether patients returned or showed a trend toward baseline levels.

\section{Statistical analysis}

The results are expressed as mean \pm SEM. Because the statistical power of the study could be limited due to the small sample of patients included, the differences between the effects of placebo and compound are shown as nonparametric confidence intervals for the four principal 

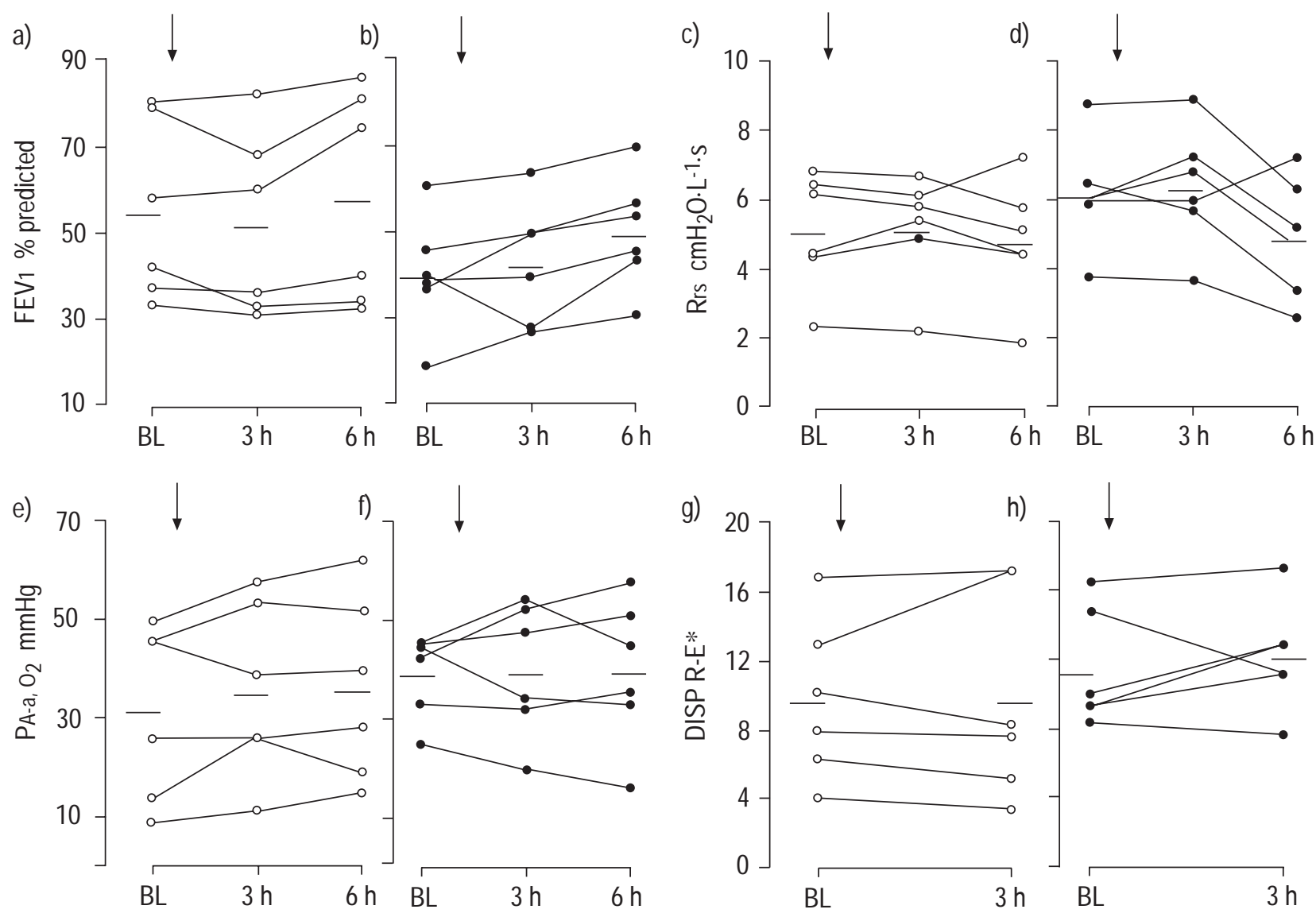

Fig. 1 - Individual and mean (horizontal bars) values of forced expiratory volume in one second (FEV1; a and b), respiratory system resistance (Rrs; $\mathrm{c}$ and d), alveolar-arterial pressure difference for oxygen $\left(P \mathrm{~A}-\mathrm{a}, \mathrm{O}_{2} ; \mathrm{e}\right.$ and $\left.\mathrm{f}\right)$ and the overal index of ventilation-perfusion ratio $\left(V \mathrm{~A}^{\prime} / Q^{\prime}\right)$ heterogeneity (DISP R-E*; $g$ and $\mathrm{h}$ ) at baseline (BL) and at 3 and $6 \mathrm{~h}$ after administration of placebo $(\mathrm{O})$ and the platelet activating factor (PAF) antagonist SR27147A $(\bullet)$. Vertical arrows indicate the time of drug administration. $(1 \mathrm{mmHg}=0.133 \mathrm{kPa}$.)

outcome gas exchange variables [17], namely $\mathrm{Pa}, \mathrm{O}_{2} P \mathrm{PA}-$ a, $\mathrm{O}_{2}$ LogSD Q (dispersion of blood flow), and an overall index of $V \mathrm{~A}^{\prime} / Q^{\prime}$ heterogeneity (DISPR-E*) (see Results section). Analysis of changes within each group was performed using Wilcoxon's test for paired data. Comparison of the effects of placebo and SR 27417A were performed using Mann-Whitney's test for unpaired measurements. Significance was set at $\mathrm{p}<0.05$ in all instances. All the analyses were carried out using version 6.0.1. of the SPSS statistical package (SPSS Inc., Chicago, IL, USA).

\section{Results}

\section{Baseline findings}

Measurements of all variables studied showed no significant differences between placebo $(\mathrm{P})$ and treatment (T) groups. In the P group, all but two patients showed moderate to severe reduction in forced expiratory volume in one second (FEV1) $(55 \pm 9 \%$ pred) and moderate increases in $\operatorname{Rrs}\left(5.09 \pm 0.70 \mathrm{cmH}_{2} \mathrm{O} \cdot \mathrm{L}^{-1} \cdot \mathrm{s}\right)$, whereas the $\mathrm{T}$ population had more pronounced airflow obstruction

Table 1. - Ventilation-perfusion distributions at baseline and $3 \mathrm{~h}$ after placebo or platelet activating factor antagonist SR $27417 \mathrm{~A}$

\begin{tabular}{lcccc}
\hline & \multicolumn{2}{c}{ Placebo } & \multicolumn{2}{c}{ SR 27417A } \\
\cline { 2 - 3 } \cline { 5 - 5 } & Baseline & $3 \mathrm{~h}$ & Baseline & $3 \mathrm{~h}$ \\
\hline Shunt \% $\bar{Q}^{\prime}$ & $0.7 \pm 0.6$ & $0.5 \pm 0.5$ & $2.0 \pm 1.1$ & $1.3 \pm 0.5$ \\
Low V'A/Q' \% $\bar{Q}^{\prime}$ & $7.3 \pm 2.4$ & $10.0 \pm 3.8$ & $3.9 \pm 2.2$ & $6.2 \pm 2.8$ \\
LogsD Q & $0.98 \pm 0.13$ & $1.10 \pm 0.17$ & $1.07 \pm 0.09$ & $1.15 \pm 0.10$ \\
LogSD V & $0.75 \pm 0.06$ & $0.68 \pm 0.07$ & $0.84 \pm 0.07$ & $0.85 \pm 0.07$ \\
Dead space \% VE & $20.8 \pm 5.6$ & $21.0 \pm 4.8$ & $24.6 \pm 3.2$ & $21.6 \pm 4.4$ \\
DISP R-E* & $9.7 \pm 1.9$ & $9.8 \pm 2.5$ & $11.4 \pm 1.4$ & $12.2 \pm 1.3$ \\
\hline
\end{tabular}

Data are mean \pm SEM. Shunt: $\%$ of $\bar{Q}^{\prime}$ to lung units with ventilation-perfusion $\left(V^{\prime} \mathrm{A} / Q^{\prime}\right)$ ratios $<0.005$; $\bar{Q}^{\prime}$ : cardiac ouput; Low $V^{\prime} \mathrm{A} / Q^{\prime}: \%$ of $\bar{Q}^{\prime}$ to lung units with $V^{\prime} \mathrm{A} / Q^{\prime}$ ratios between 0.005 and 0.1 ; LogsD Q: dispersion of blood flow distribution; Mean Q: mean distribution of blood flow; LogSD V: dispersion of ventilation distribution; Mean V: mean distribution of ventilation; $V \mathrm{E}$ : minute ventilation; DIP R-E*: dispersion of retention minus excretion of inert gases corrected for dead space. 
(FEV1 $40 \pm 6 \%$ pred; $R \mathrm{rs}, 6.17 \pm 0.65 \mathrm{cmH}_{2} \mathrm{O} \cdot \mathrm{L}^{-1} \cdot \mathrm{s}$ ) (fig. 1). The degree of gas exchange impairment in both subsets of patients was however similar to the spectrum of abnormalities shown in our previous studies [18] $\left(\mathrm{PA}-\mathrm{a}, \mathrm{O}_{2}\right.$ $4.2 \pm 1.0$ versus $5.2 \pm 0.5 \mathrm{kPa}$ for the $\mathrm{P}$ and $\mathrm{T}$ groups, respectively) (fig. 1); yet, the $\mathrm{P}$ group exhibited less hypoxaemia $\left(P a, \mathrm{O}_{2}, 10.6 \pm 1.0\right.$ versus $9.1 \pm 0.5 \mathrm{kPa}, \mathrm{P}$ versus $\mathrm{T}$ groups but the same degree of hypocapnia $\left(P \mathrm{a}, \mathrm{CO}_{2}\right.$, $4.4 \pm 0.08$ versus $4.6 \pm 0.03 \mathrm{kPa}, \mathrm{P}$ versus $\mathrm{T}$ groups). Although patients in the $\mathrm{P}$ group showed a slightly lower RR $\left(17 \pm 3\right.$ frequency $\left.\cdot \mathrm{min}^{-1}\right)$, both $V \mathrm{E}\left(6.9 \pm 0.6 \mathrm{~L} \cdot \mathrm{min}^{-1}\right)$ and $V^{\prime} \mathrm{O}_{2}\left(213 \pm 15 \mathrm{~L} \cdot \mathrm{min}^{-1}\right)$ were close to those observed in the $\mathrm{T}$ group $\left(20 \pm 4\right.$ frequency $\cdot \mathrm{min}^{-1}, 9.9 \pm 1.3 \mathrm{~L} \cdot \mathrm{min}^{-1}$, and $279 \pm 33 \mathrm{~L} \cdot \mathrm{min}^{-1}$, respectively). Similarly, haemodynamic variables were close in each treatment arm: HR $101 \pm 5$ and $95 \pm 8$ beats. $\min ^{-1}$, mean $P_{\mathrm{S}} 84 \pm 4$ and $94 \pm 4$ $\mathrm{mmHg}, Q^{\prime} 7.0 \pm 0.4$ and $7.3 \pm 0.4 \mathrm{~L} \cdot \mathrm{min}^{-1}$, for $\mathrm{P}$ and $\mathrm{T}$ groups, respectively.

Table 1 shows mean baseline measurements of $V \mathrm{~A}^{\prime} / Q^{\prime}$ distributions, similar to those observed in previous studies [18]. The LogSD Q, a marker sensitive to the presence of alveolar units with both normal and low $V \mathrm{~A}^{\prime} / Q^{\prime}$ ratios (excluding shunt $\left[V_{\mathrm{A}^{\prime}} / Q^{\prime}\right.$ ratios $\left.<0.005\right]$ ), showed a bimodal profile associated with perfusion to areas with normal $V^{\prime} / Q^{\prime}$ ratios (between 0.1 and 10) in four patients in the $\mathrm{P}$ group and in three in the $\mathrm{T}$ group, whereas the amount of intrapulmonary shunt was marginal. The LogSD Q was increased in five patients in the $\mathrm{P}$ group (range 0.52-1.28) and in all patients in the T group (range $0.83-1.42$ ) (normal values $<0.60$ [16]). In addition, DISP $\mathrm{R}-\mathrm{E}^{*}$, i.e. the root mean square difference among measured retentions $(\mathrm{R})$ and excretions $(\mathrm{E})$ of the inert gases corrected for the dead space (normal values <3.0 [16]), was elevated in all of the patients in the two subsets (4.1116.9 and $8.4-16.5$ for $\mathrm{P}$ and $\mathrm{T}$ groups, respectively) (fig. 1) [14]. In contrast, the dispersion of the ventilation distribution (LogSD V), a descriptor sensitive to the presence of alveolar units with both normal and high $\mathrm{VA}^{\prime} /$ $Q^{\prime}$ ratios, was mildly altered and showed a broadly unimodal pattern, while inert dead space $\left(V_{\mathrm{A}}^{\prime} / Q^{\prime}\right.$ ratios $>100$,) was moderately reduced. Moderate neutrophilia $\left(10.7 \pm 2.2\right.$ and $11.2 \pm 0.9 \times 10^{9}$ cells $\cdot \mathrm{L}^{-1}$ for the $\mathrm{P}$ and $\mathrm{T}$ groups, respectively) was present in most of the patients.

\section{Effects after placebo and SR 27417A}

Platelet aggregation tests by both 40 nM PAF (72 \pm $6 \pm 2 \%)$ and $80 \mathrm{nM}$ PAF $(81 \pm 7-6 \pm 3 \%)$ were significantly abolished $(\mathrm{p}<0.01$, each) $3 \mathrm{~h}$ after administration of the compound but not after vehicle $(56 \pm 7-63 \pm 15 \%$ and $51 \pm 6$ $-72 \pm 11 \%$, respectively). However, compared with placebo, SR 27417A did not affect airflow rates, $R$ rs, systemic haemodynamics and pulmonary gas exchange parameters at both 3 and $6 \mathrm{~h}$ after the intake of the anti-PAF compound (fig. 1). Similarly, the severity of $V \mathrm{~A}^{\prime} / Q^{\prime}$ heterogeneity, as assessed by its major indices, more specifically LogSD Q and DISP R-E*, remained unchanged $3 \mathrm{~h}$ after the administration of the drug (table 1, fig. 1). The nonparametric confidences interval of the differences between placebo and drug for the principal gas exchange outcomes were: $P \mathrm{a}, \mathrm{O}_{2}, 0.9--2.3 \mathrm{kPa} ; P \mathrm{~A}-\mathrm{a}, \mathrm{O}_{2}-1.1-1.8 \mathrm{kPa} ; \operatorname{logSD} \mathrm{Q}$, $-0.17-0.21$; and, DISP R-E*, $-4.03-3.32$ [17]. No significant changes in peripheral neutrophil counts were observed.

\section{Discussion}

The present investigation of patients with AA failed to show a beneficial effect with a PAF antagonist on either gas exchange end-points variables, including $V \mathrm{~A}^{\prime} / Q^{\prime}$ relationships, or, less specifically, on functional outcomes of airways obstruction (FEV1, Rrs), or both. This is the first study to date testing the efficacy of a PAF receptor antagonist in the setting of spontaneously occurring natural AA needing hospitalization. It was postulated that pulmonary gas exchange abnormalities may represent a more sensitive marker of response to therapy than spirometric variables in view of the findings that acutely inhaled PAF provokes in both healthy individuals and patients with mild asthma profound gas exchange disturbances more likely related to abnormally increased airway microvascular permeability $[4,6,18-21]$. Therefore, the addition of a PAF receptor antagonist to patients recovering from AA but still showing signs of moderate to severe hypoxaemia and airways obstruction was expected to show a more rapid improved functional response. Indeed, any measures that would cause a more rapid reversal of these abnormal functional end-point variables would be beneficial to the current management of AA. Although the SR27417Atreated patients showed more severe airways obstruction and gas exchange abnormalities than the placebo-treated group, this was not believed to account for the lack of effect of the PAF antagonist.

The compound, SR 27417A, is a new selective, second generation class of PAF receptor antagonists that has been shown to have potent and long-lasting effects against PAFinduced gas exchange abnormalities [13]. It has previously been shown that, in patients with stable mild asthma, pretreatment with oral SR27417A, at the same oral dose used in the present study, inhibited all PAF-induced systemic effects and abnormal neutrophil kinetics while effectively minimizing both bronchoconstriction and gas exchange disturbances in a laboratory-induced model of human asthma using PAF (18 $\mu \mathrm{g})$ [13]. The present study complements and extends the latter findings, as it assesses the efficacy of the same drug and the same dosage in natural, spontaneous AA. In addition, SR 27417A in the current study inhibited almost completely the in vitro platelet aggregation tests provoked by PAF, to a similar degree to that observed in the previous study [13], thereby indicating the efficacious bioactivity of the compound. Therefore, PAF was not able to meet one of the most important Koch's related postulates as a putative inflammatory mediator in asthma [1], namely the reduction or abolition of naturally occurring $\mathrm{AA}$ when its effects were effectively blocked.

Systemic glucocorticosteroids may inhibit phospholipase $\mathrm{A}_{2}$, and therefore the production of lipid mediators such as PAF [22]. Yet, there are no data available regarding its effects on PAF in patients with asthma. Similarly, salbutamol could modulate PAF activity. A previous study, has demonstrated that inhaled salbutamol (300 mg) given conventionally, fully inhibited all systemic, cellular and respiratory effects of inhaled PAF in patients with mild asthma, thereby suggesting potent anti-oedema properties of $\beta_{2}$-adrenergic agonists [21]. It is therefore conceivable that the energetic treatment with both systemic glucocorticosteroids and nebulized salbutamol administered to the current patients prior to SR 27417A 
could have inhibited, at least in part, the actions of any PAF that was endogenously released, thereby limiting any beneficial effects of the PAF antagonist. It would have been unethical, however, to withhold both systemic glucocorticosteroids and nebulized bronchodilators and it was therefore not possible to test this PAF antagonist without the administration of conventional anti-asthma medication. A third critical comment refers to the time course of the study. The drug may be more active at an earlier stage of the asthma attack, possibly within the first $24 \mathrm{~h}$, when it is thought that most of the inflammatory mediators are more aggressive. Nevertheless, despite these negative results and the small number of patients with AA studied in this pilot investigation, a clinical trial with PAF receptor antagonists including a major population of individuals with AA might be warranted. Patients with AA would be expected to have thickening of the airway mucosa due to abnormally increased permeability and mucous plugging occluding the lumen of peripheral airways [18]. Since PAF potentially enhances plasma extravasation and induces hypersecretion within the airways $[18,19]$, these PAF effects may be those on which to focus therapy with PAF antagonists [23].

Taken altogether, it is concluded that SR 27417A, one of the most potent platelet-activating factor receptor antagonists currently available, does not show promise as a complementary drug that can be of use for the treatment of acute asthma. Accordingly, these findings minimize the potential pathogenic role of an endogenous release of platelet-activating factor, as a relevant mediator of airway inflammation in acute exacerbations of the disease.

\footnotetext{
Acknowledgements. The authors are grateful to G. Escolar, Servei d' Hemoterapia, Hospital Clinic, Barcelona, for the studies of platelet aggregation, L. de Jover, Departament de Salut Pública, Divisió de Ciències de la Salut, Universitat de Barcelona, for unselfish statistical advice, E. Bastida, Sanofi Winthrop, SA, for input and support, and to the nurses and technicians of the Servei de Pneumologia i Al.lèrgia Respiratòria, for their expertise and cooperation.
}

\section{References}

1. O'Byrne PM, Israel E, Drazen JM. Antileukotrienes in the treatment of asthma. Ann Intern Med 1997; 127: 472480.

2. Chung KF. Platelet-activating factor in inflammation and pulmonary disorders. Clin Sci 1992; 83: 127-138.

3. Stenton SC, Court EN, Kingston WP, et al. Plateletactivating factor in bronchoalveolar lavage fluid from asthmatic subjects. Eur Respir J 1990; 3: 408-413.

4. Rodriguez-Roisin R, Félez MA, Chung KF, et al. Plateletactivating factor causes ventilation-perfusion mismatch in man. J Clin Invest 1994; 93: 188-194.

5. Barnes PJ, Chung KF, Page CP. Platelet-activating factor as a mediator of allergic disease. $J$ Allergy Clin Immunol 1988; 81: 919-922.

6. Félez MA, Roca J, Barberà JA, et al. Inhaled platelet activating factor worsens gas exchange in mild asthma. Am J Respir Crit Care Med 1994; 150: 369-373.

7. Adamus WS, Heuer HO, Meade CJ, Schilling JC. Inhibitory effect of the new PAF acether antagonist WEB-2086 on pharmacologic changes induced by PAF inhalation in human beings. Clin Pharmacol Ther 1990; 47: 456-462.

8. O'Connor BJ, Uden S, Carty TJ, Eskra JD, Barnes PJ, Chung KF. Inhibitory effect of UK,74505, a potent and specific oral platelet activating factor (PAF) receptor antagonist, on airway and systemic responses to inhaled PAF in humans. Am J Respir Crit Care Med 1994; 150: 35-40.

9. Spence DP, Johnston SL, Calverley PM, et al. The effect of the orally active platelet activating factor antagonist WEB 2086 in the treatment of asthma. Am J Respir Crit Care Med 1994; 149: 1142-1148.

10. Kuitert LM, Angus RM, Barnes NC, et al. Effect of a novel potent platelet-activating factor antagonist, Modipafant, in clinical asthma. Am J Respir Crit Care Med 1995; 151: 1331-1335.

11. Shindo K, Koide K, Fukumura M. Enhancement of leukotriene B4 release in stimulated asthmatic neutrophils by platelet activating factor. Thorax 1997; 52: 10241029.

12. Miwa M, Miyake T, Yamaoka T, et al. Characterization of serum platelet-activating factor (PAF) acetylhydrolase: correlation between deficiency of serum PAF acetylhydrolase and respiratory symptoms in asthmatic children. J Clin Invest 1988; 82: 1983-1991.

13. Gómez FP, Roca J, Barberà JA, Chung KF, Peinado VI, Rodriguez-Roisin R. Effect of a platelet-activating factor (PAF) antagonist, SR 27417A, on PAF induced gas exchange abnormalities in mild asthma. Eur Respir $J$ 1998; 11: 835-839.

14. International Report on Asthma. International Asthma Management Project and NHLB Institute. International consensus report on diagnosis and treatment of asthma. Eur Respir J 1992; 5: 601-641.

15. Ferrer A, Roca J, Wagner PD, Lopez FL, RodriguezRoisin R. Airway obstruction and ventilation-perfusion relationships in acute severe asthma. Am Rev Respir Dis 1993; 147: 579-584.

16. Roca J, Wagner PD. Contributions of multiple inert gas elimination technique to pulmonary medicine. 1 Principles and information content of the multiple inert gas elimination technique. Thorax 1994; 49: 815-824.

17. Conover WJ. Practical nonparametric statistics. 2nd ed. New York (NY): John Wiley and Sons Inc. 1980.

18. Rodriguez-Roisin R. Acute severe asthma: pathophysiology and pathobiology of gas exchange abnormalities. Eur Respir J 1997; 10: 1359-1371.

19. Chung KF. Platelet activating factor revisited. Thorax 1997; 52: 1019-1020.

20. Roca J, Félez MA, Chung KF, et al. Salbutamol inhibits pulmonary effects of platelet activating factor in man. Am J Respir Crit Care Med 1995; 151: 1740-1745.

21. Dáz O, Barberà JA, Marrades R, Chung KF, Roca J, Rodriguez-Roisin R. Inhibition of PAF-induced gas exchange defects by beta-adrenergic agonists in mild asthma is not due to bronchodilation. Am J Respir Crit Care Med 1997; 156: 17-22.

22. Barnes PJ. Molecular mechanisms of steroid action in asthma. J Allergy Clin Immunol 1996; 97: 159-168.

23. Nadel JA. Genetics reveals importance of platelet-activating factor in asthma and possibly other inflammatory states. J Clin Invest 1997; 97: 2689-2690. 